\title{
Understanding experiences in hospice: Exploring temporal, occupational, and relational dimensions using pictor technique
}

\author{
Abstract \\ Temporality, occupation, and relationships are identified as discrete factors that impact \\ quality of life for individuals at the end of life and those around them. However, scholars, \\ practitioners, and educators require insights regarding whether and how interactions between these \\ factors shapes this quality of life. This study is framed by an understanding that meaning is \\ negotiated between people through social interaction and occupational engagement in temporal \\ contexts. We conducted in-depth interviews with 9 patients and 10 family members, incorporating \\ the Pictor visual elicitation technique. Analysis was conducted through an iterative process \\ involving open and selective coding. Findings are described as three main processes: 1) \\ experiences of temporal rupture, 2) diminished significance of clock time, and 3) shifts in \\ occupational priorities. Participants' perspectives may help carers understand how to foster \\ positive temporal experiences and quality of life for patients and those who love them.
}




\section{Understanding experiences in hospice: Exploring temporal, occupational, and relational dimensions using pictor technique}

\section{Introduction}

Individuals at the end of life (EoL) and those around them have temporal experiences that differ from those in the world around them (Robertson, 2014). Their temporal experiences are both influenced and mitigated by occupational engagement and disengagement, and by the relationships in their lives. Occupation - contextually-informed engagement that holds and creates meaning contributes to a sense of being, becoming, and belonging (Hammell, 2014; Huot et al., 2019; Wilcock, 1998); affects well-being; and offers structure to people's lives (Townsend \& Polatajko, 2007). Examples of occupations include activities associated with caring for one's self, such as bathing; contributing to the community, such as volunteering as a hospice visitor; and enjoyment, such as knitting. According to Essential Yeh and McColl's (2019) robust literature review, occupation supports quality of life at EoL because it is an essential part of meaning-making. The authors describe how it helps people overcome uncertainty, and prevents the loss of valued identities and roles (Yeh and McColl, 2019). Meaningful occupations take on six orientations at EoL: living with death, reworking everyday life, being guided by the will of the body, giving priority to relationships, attending to the small things, and embodying existential orientations (Lala \& Kinsella, 2011). While cure for those with terminal illness may be impossible, occupational engagement contributes to the goal of facilitating quality EoL experiences (Lala \& Kinsella, 2011). Occupational engagement at EoL supports quality of life; however, there is a paucity of literature examining the mechanisms by which occupation facilitates quality of life (2015). This study helps address this gap by examining how occupation interacts with dimensions of 
temporality and relationships. This may shed light on mechanisms by which occupation impacts quality of life.

In addition to facilitating quality of life, occupation can strengthen relational ties and can be shaped by temporal and spatial locations (Morrison et al., 2017). For example, engaging together in the occupation of scrapbooking can strengthen relational ties as individuals interact and reflect on their co-production. Moreover, time becomes precious at the EoL and therefore experiences of time are linked with quality of life (Adam, 2013; Chochinov, 2011; Robertson, 2014). For example, Waterworth, Gott, Raphael, and Barnes (2011) describe time impacting quality of life: healthcare providers' rushing through caregiving occupations interferes with patient quality of life. James, Andershed, and Ternestedt (2009) found that family members experienced insufficient quality of time in a hospital palliative care setting to establish a meaningful relationship with healthcare professionals.

Palliative care, of which hospice-based EoL care is a part, is a person-centred approach aimed at improving and maintaining quality of life for patients with terminal diagnosis and those they love (World Health Organization, 2018). Provision of person-centered care depends on understanding how patients and families experience quality of life (Schellinger et al., 2018). Relationships support patients' coping and positive bereavement processes for both patients and families at EoL (Chiu et al., 2010). When patient quality of life is maintained, those family members who provide care at EoL experience less complicated bereavement (Dumont et al., 2008).

The central aim of hospice care is to keep people as comfortable as possible until they die. Although patients and caregivers commonly express satisfaction with hospice care, there remain challenges in achieving this aim (Jenkins \& Codling, 2013). Although estimates of prevalence vary, a notable number of hospice patients experience depression and anxiety, and there are 
grounds to think such conditions are under-reported (Hayes et al., 2017; Irwin et al., 2008; Kozlov et al., 2019). In addition, loneliness and lack of relational connectedness impact hospice patients' quality of life (Bale et al., 2016; Rokach, 2016; Sawyer et al., 2019; Untas et al., 2011).

Although temporality, occupation, and relationships are identified as discrete factors that impact quality of life (Andershed, 2006; Ellingsen et al., 2013; Lala \& Kinsella, 2011; Larson \& Zemke, 2003), there is little insight regarding whether their interaction may shape quality of life for individuals in inpatient hospice EoL care and for their families. Previous studies focus predominantly on one of the factors in isolation, and scholars, practitioners, and educators require insight into the interaction of these factors that shape the quality of EoL to foster enriching and meaningful EoL experiences (Kuhl et al., 2010; Tang et al., 2004). Bringing awareness to these processes can foster more sensitive EoL care that is attuned to the complex meaning making of patients and families and can enhance how we teach novice healthcare practitioners to communicate and interact with people at EoL.

\section{Theoretical lens}

This study was framed by social temporal theories of time. Clock time, or objective time, is that which is measured in minutes. Temporality is the individual's subjective experience of time, and may involve a divergence between linear clock time and experiences of it (Ellingsen et al., 2013; Larson, 2004; Lövgren et al., 2010). Temporality is described as more diverse than clock time, to include embodied and situated time, such as biological, relational, institutional, and so-on (Ellingsen et al., 2013; Lövgren et al., 2010; Nimmon et al., 2018). The existential and embodied experiences of dying may cause dying people to experience temporality differently than those around them (Giuliani et al., 2015; Robertson, 2014). This divergent temporality may contribute to a sense of alienation, because the dying individual is living outside clock time, in which the 
majority of society, healthcare professionals, and perhaps their families operate (Giuliani et al., 2015).

Temporality may also impact satisfaction with daily experiences (Larson, 2004) and therefore quality of life. Occupational engagement may shift an individual's temporality. According to Larson (2004, p. 71), "the study of temporality is a window to understanding the dynamic interplay of daily occupation and lived experience." Relationality - the state of being relational - is another factor in this interaction. Temporality affects patterns of human interactions and of occupation, and the coordination of occupation among relational beings (Larson \& Zemke, 2003).

\section{Research Question}

This study employs the understanding that meaning is negotiated between people through social interaction and occupational engagement in a temporal context (Gumperz, 1992; Larson \& Zemke, 2003). This allows us to acknowledge that the experience of relationships, temporality, occupational engagement, and quality of life are neither static nor independent of one another (Nimmon, 2014). Given the established knowledge regarding the impact of occupation, relationships, and temporality on quality of life at EoL and the gap in literature regarding their interaction, our driving research question was "in what ways might relationships, temporality, and occupation inform one another and shape quality of life at the EoL in hospice?"

\section{Methodology \& Methods}

\section{Context}

The study was developed in partnership with hospice-based palliative care professionals: a nurse, social worker, and physician. They supported the development of sensitive ethical recruitment approaches by suggesting that the hospice team identify potential participants and 
provide them with study information. They also invited the researcher conducting interviews to spend time at hospice so she would become familiar to the team. The study was approved by the host university and health authority ethics boards, and all participants provided written informed consent at the outset of the interview and ongoing verbal consent. This included explicit consent to publish anonymized (through pseudonyms) quotations. The study was conducted at a publiclyfunded, inpatient hospice facility in a suburban setting under the auspices of a Catholic healthcare authority. Individuals admitted to the hospice had up to three month's life expectancy, in what Sercu, Beyens, Cosyns, Mertens, Deveugele, and Pype (2018) refer to as the terminal phase of EoL. Within the facility there were 24-hour nursing staff, healthcare aids, cooking staff, volunteers, a social worker, and rotating physicians. The facility itself was accessible by public transit and located in a rural area near to a metropolitan area. It had 14 private rooms, multiple living rooms, shared dining spaces, and a patio. Inclusion criteria for all participants were ability to give informed consent and being over age 19. Additionally, patients needed to be admitted to the facility and have sufficient medical stability and cognitive function to participate.

\section{Data collection}

Data, collected August 2016 through June 2018, included in-depth interviews with hospice patients $(n=9)$ and individuals they identified as important in their care network (termed significant others): spouses $(n=3)$, adult children $(n=3)$, siblings $(n=2)$, friends $(n=2)$, and staff $(n=1)$. See table 1 for an outline of the networks from which participants were included in the interviews. Interviews lasted approximately 60 minutes and took place at hospice in the patient room or a quiet room within the facility. 
Table 1. Participant networks included in interviews

\begin{tabular}{|c|l|}
\hline $\begin{array}{c}\text { Net } \\
\text { work }\end{array}$ & Interviewees \\
\hline 1. & Patient + 2 family members \\
\hline 2. & Patient + spouse \\
\hline 3. & Patient + spouse \\
\hline 4. & Patient + family member \\
\hline 5. & Patient + 2 friends \\
\hline 6. & Patient + spouse and family member \\
\hline \multicolumn{2}{|c|}{} \\
\hline \multicolumn{2}{|c|}{ single interviews with 3 patients, 1 family member, 1 hospice staff member } \\
\hline
\end{tabular}

Patients and family were asked to complete Pictor charts. Pictor is a data collection technique that has been used with people with advanced disease (King et al., 2013). It is considered an appropriate technique to use with patients who are frail or might experience distress because it incorporates natural breaks from talking during an interview and fosters reflection (Hardy et al., 2012). Participants were asked to create a chart that captures their experiences of supportive relationships while in hospice, and to indicate where such relationships may have differed one month prior to admission. Participants were presented with a large paper with a circle in the middle, representing the patient, and arrow-shaped stickies in three colours. Participants could write or have the interviewer write names on the stickies and place them on the paper in a position relative to the patient. Using the Pictor technique, the participant created a chart representing who was involved in shaping the patient's quality of life. Participants were asked to lay out the arrows to help them tell the story of the patient's experience and the role of others in it. Participants used aspects such as the direction of the arrows and proximity to other arrows to indicate features of relationships. The Pictor technique was used with family and patients, but not with hospice staff due to their time constraints. The charts captured participants' thinking, and allowed them to represent their thoughts about the meaning of their relationships at EoL. Thus the 
chart, as a graphical representation of the participant's experience, bolstered an in-depth exploration of roles and relationships (Hardy et al., 2012). The charts formed part of the data collected for analysis (see Figures 1-3), all names are anonymized.

Figure 1: Patient's Pictor Chart

Insert figure 1

Figure 2: Family member's Pictor Chart

Insert figure 2

Figure 3: Family member's Pictor Chart

Insert figure 3

\section{Analysis}

Interviews were transcribed verbatim, identifying information replaced with pseudonyms. Team members include an occupational therapist and occupational scientist, two social scientists, and a palliative care physician. First, all transcripts were read and re-read. Then each transcript was coded by assigning a one to three-word code to meaning chunks (open coding). As major ideas emerged, selective coding was used to further refine understandings of the data. The Pictor charts were used to corroborate and crystalize the emerging insights by comparing family's and patients' charts to understand the variety of perspectives.

Knowledge of occupational science theory sensitized understandings of the data, causing the team to notice within the data descriptions of experiences of occupational engagement and how these experiences interacted with temporality and relationships. As insights about temporal experience emerged from the data, the team drew on existing theory regarding temporal experiences in EoL to contextualize insights. Considering our initial research question regarding relationships and quality of life, we became attentive to how emerging insights about time and 
occupation may interact with those regarding relationships and quality of life. Our interpretations of the data were informed by an understanding that meaning is negotiated, fluid, and dynamic informed how the researchers understood the data. Latter stages of data analysis were thus sensitized by existing knowledge regarding temporality, relationships, occupation, and quality of life. At this latter stage we refined the research question to reflect the main insights arising in data analysis.

We endeavoured to promote trustworthiness of the research process, data, and findings. Team members engaged in reflexive practices including journaling before and after interviews, during data analysis, and throughout writing. We also met throughout the research process to discuss the process, findings, and any ethical or methodological issues. The first transcript was reviewed by the whole team, who then met to discuss any variations in the insights arising from the transcript and suggestions for future analysis. During data analysis team members met regularly to resolve any inconsistencies or diverging perspectives.

\section{Findings}

The data highlight ways in which temporality impacts relational and occupational experiences. We explore the findings as three main processes: 1) experiences of temporal rupture, 2) diminished significance of clock time, and 3) shifts in occupational priorities. Quotations are represented using pseudonyms.

\section{Experiences of temporal rupture}

Temporal rupture occurs when a significant life event disturbs the usual patterns of occupation, which appeared to be occurring in the lives of all participants, from the initial appearance of symptoms to hospice admission. For some, this rupture seemed to be an ongoing experience, while others were able to move into a new, stable experience of time. 
Losing doing occupations due to temporal rupture. Temporal rupture can sometimes disrupt quality of life for patients and family. One patient describes a moment of temporal rupture: "all of a sudden, one morning I wake up and just, boom, I fell flat on my face [...] And my life was over [...] Just like that, boom." For this patient, in that moment of temporal rupture, his quality of life was shattered because he could no longer engage in his valued occupations in the ways he always had. He goes on to describe experiencing life after the rupture, but still sensing the loss of quality of life:

So many people they come, you know, they just keep coming and coming and coming and coming. I just couldn't believe it [... visitors coming makes life now] very, very, very much better $[\ldots]$ there's just so many people that come up $[\ldots]$ what I miss $[\ldots]$ a very good quality of life. My quality of life was very, very, very good. Now I don't know what to do [...] See after I'm dying, you know, I'm still a little bit sense of humour [...] It's very, very important, you know. Like, I mean, it's the most important thing.

For this individual, temporal rupture, with its disruption of normal patterns of occupation (e.g. no longer living at home and going for daily walks), has impacted his quality of life; however, particularly owing to relationships with his many visitors and his good humour, he is able to build a different kind of quality of life in hospice. Participants describe the loss of doing occupations as a blow to quality of life. Another patient describes his temporal rupture as a sense of being stalled, just waiting for the end to come, and yet wanting time to remain stalled:

You're stalled and you don't - well, you want to be stalled because if you keep moving forth the only place you're moving towards is your death. And if you're scared to die, must be fearful. You have to learn to let go and just go with it all. I'm still learning that. Time is different $[\ldots]$ it's eating you up. You become worse. You're running - you become weaker 
and weaker and you can do less and less things. It's kind of demeaning in a way. You give up all these things you normally could do yourself and you can't do it anymore. Your dignity - you lose all your dignity. But I try and keep it up as best as I can.

He knows time is continuing to pass because he is becoming weaker and less able to engage in occupations that were once done without thought, such as dressing himself. Jeff experiences temporal rupture as a challenge to his doing occupations, such as bathing himself, and therefore a threat to his quality of life (described as demeaning). However, he later describes coming to a state where he is not feeling the impact of temporal rupture.

Gaining becoming and belonging occupations during temporal rupture. One patient described how he moved to a more relational form of engagement, where he is at peace and engaged in occupations focussed on belonging to others and becoming who he wants to be:

Loving each and every person [...] That's what I'm trying to portray across. That's who I'm trying to become inside. Letting the love out inside me is to share towards everyone [...] from my heart. It's like a flower blossoming in my heart and reaching forth [...] Go out in a blaze of love if I can [...] that is it in a nutshell what I'm trying to do. How successful I'll become, well, time will only tell [...] You're completely alive and even going off to death, you're going off alive. Nothing to fear and everything's perfect. Going home.

The son of one patient talks about his experience of temporal rupture as a time of unpredictability, not knowing when his mother will pass. He expresses the unpredictability of death as draining, while at the same time he appreciates how important and also sacrificial time with his mother is. 
At this stage we're kind of selfish [...] I want to see her longer [...] But don't forget, patient is suffering [...] quite dilemma. I want to see her longer and yet she has to suffer. That is difficult $[\ldots]$ unknown factor - could be two months, six months, tomorrow. So that is totally unpredictable and cannot be prepared for. Again, it's straining our strength too because, like, I live in [city an hour's drive away] [...] I want to see her as many seconds, minutes, as much as possible. But physically I have to drive - physically tired. But I think ultimately, I think this tired is worthwhile. Because I said to you, I don't want to regret after she's dead - oh, I should have done that [...] my parents have sacrificed for us for so many years without any complaint. And now our return. This little thing, I would complain?

Occupations that facilitate a sense of belonging to his family appear to be particularly important to this family member during a time of temporal rupture.

Establishing new occupational routines to recover from temporal rupture. The spouse of one patient describes trying to move back toward a synchronous experience of clock time by establishing a new routine following temporal rupture:

It's not like we're running away from the idea that he's dying. But just every day it doesn't it's not the major thing. 'Cause I think it would be horrible for him just to talk about dying every day. He kind of - he has a normal life. It's way not normal. But he's made a normal life here. You wake up, you have coffee, the nurses come in, then you have visitors. You it's a new routine [...] It's important.

All of those interviewed for this case described this "new routine" from their own perspectives. For all of them, the new routine was related to temporal rupture and an attempt to establish stability and a sense of normalcy. The spouse describes her desire to plan the patient's time and maintain some semblance of control in the midst of temporal rupture: 
My relationship with time changed when he got the diagnosis [...] I remembered thinking we have no future [...] We can't plan [...] I used to be - I am, a very planful person [...] I don't have time [...] Planning, you have to have control of time. I don't have that.

Time becoming precious in light of temporal rupture. Many participants describe experiences of temporal rupture - whether they are the individual dying or not. A spouse describes the temporal rupture she and her family experienced, and how time with her partner (the patient) became precious as a result of expecting death:

Time is precious with him, because I don't know when and we do know it could happen. I mean, they keep telling me, well, they don't know with heart patients. So, if I get a call I'm always, oh, is this it? So, when I come in it is precious [...] I'm aware that when that day comes when I've lost him, there's no going back [...] so time is precious 'cause I know that will happen.

During temporal rupture, time appears to become precious for some because it is a resource fleeting with an unknown trajectory. Other occupational pursuits are put on hold because this occupation of being with and belonging to one another is more important.

Another spouse describes how temporal rupture has impacted her occupational engagement, where now she is engaged only in occupations that involve caring for her husband, belonging to and with him, and preparing for death. She is also anticipating what will happen when she experiences another rupture at his death: “it's going to be very hard. I think now because I'm here every day [...] now I'm busy all the time so when anything happens, it's going to be hard."

The temporal ruptures described by participants occur in relational contexts and impact their occupational engagement. Often, this leads to a decrease in the importance placed on clock time and subsequent shifts in occupational priorities. 


\section{Diminished significance of clock time}

Clock time orders much of the world, including the healthcare environment (Waterworth et al., 2011). However, our data suggest that for some patients and families, clock time seems to be losing importance:

I don't really think about, you know, oh, Tuesday's going to be busy, Wednesday's not going to be busy, Thursday's going to be - I don't think of it that way [...] I'm getting some theories on time, like, it doesn't exist. There is no time. When I wake up in the morning, I have no idea whether it's about to get dark out or about to get light out. Or whether I should be going to sleep or waking up. It's like this building's magic, and there is no time in [hospice] [...] I've decided to just go with that. What day is it? I don't know, who cares. I don't have anything to do [...] time just doesn't exist in this world. I think because it doesn't matter. (Patient)

This patient's lack of occupation (“don't have anything to do") is connected with her ambivalent attitude toward clock-time. Following the temporal rupture that occurred at her cancer diagnosis, she appears to have embraced a new relationship with time rather than trying to move toward synchronicity with clock-time. For her, an embodied experience of time has taken precedence:

When I open my eyes, I look out the window of my room and I don't know whether it's breakfast, lunch, or dinner. But I know if it's time to eat they'll feed me [...] It really doesn't matter what time it is. If I'm thirsty it's time for a drink. If I'm hungry it's time to eat something. If I'm tired, I can lean over and go sleep. My life is absolutely perfect. And it's so hard to try and, like, how would you explain that to somebody? 
In contrast with the earlier description of stalled time from a different patient, in the present case moment to moment temporality seems to be connected positively with a quality of life, except that it creates some tension in relationships with those for whom clock-time remains central:

My sister still has to get her university degree and my daughter still has to pay her mortgage. So, time exists for everybody except me [... my time] just stopped [...] There is no time in my world. Except for everybody else. 'Cause everybody else's time is still moving.

This patient is not alone in their experience of relational tension due to differing temporality and priorities. The son of another patient describes how his mother focusses on clock time when scheduling visitors:

Mom schedules which is - she makes sure that if people are planning to visit, they clear it through her first, so that he can have people at different times of the day. And everyone doesn't arrive at once and then he's left bored for the rest of the day. So, I think that's kind of a nice thing.

However, he (the son) provides a differing perspective on this scheduling: "[Mother] makes the schedule because she doesn't want it rushed for everybody's concern, so people have a quality of time with me." The patient describes the reason for the schedule as being about the quality of time. Due to his physical state, he is only able to actively engage with a few people at once, and for a limited time each day. Therefore, for him, the schedule is more about embodied time and related occupational dimensions (i.e. how long he can actively engage in social occupations) than it is clock time. The quality of occupation is mitigated by his embodied experiences, and the schedule acts as a bridge between others' experience of clock time and the patient's experience of embodied time. 
Facilitating quality of life by de-emphasizing clock-time. Some participants suggest that de-emphasising clock time's importance, framed as others' slowing down, might improve patient experiences in hospice. For example, one patient shares:

One thing they can improve here because - seems like there is a little bit of lack of people listening. A lot of times it's staff [...] A lot of times you say something, and they come out with something else. So that's not listening [...] We all should slow down.

Busy providers' days are likely dictated by clock time, so they may find it difficult to slow down and allow relational time to shape actions. The friend of another patient also addresses the importance of listening and taking time to build relationship:

We could talk about how listening, have time [...] There's a sense of busy-ness, even though it's not busy, it's like in any hospital, you walk out and say, 'I can hear Jeff's [...] the air coming through his oxygen. It is too high because I never hear it. They come in within a minute and they leave. It's this perfunctory, and they've got other stuff [...] You would want to have them invest time. And they do [...] I don't expect them [...] I don't know how to build dignity because they are busy [...] It's the five minutes. It's not long and they could say, 'How do you feel now that your sister has gone home?' Because they will be there for weeks, not like at hospitals for 4 days. You build relationships.

She talks about time as belonging to the patient, and the importance of that being prioritized over clock time, or other occupational concerns:

We want to give agency to the person who is dying and not us. Anything that takes dignity away from them, and towards the institution. It's almost like this is Jeff's time, this is 'his.' I enjoyed it. I felt it was really his time. To have people around who recognize that. 
Offering a contrary perspective, another patient's son describes how the staff in hospice do provide attentive care where they are present with patients:

Here, you know, because it's a smaller operation, so what, three staff four staff look after only eight beds. So, kind of like a more attentive and caring. Not - I don't mean that the services in other two hospitals, not caring. But what I mean, is they have to look after so many patients. Kind of like spend less time with you, each individual over there [...] [hospice staff] are selfless. I mean, they really dedicate himself or herself to the patient, to society, to community.

A healthcare staff member, also addresses the importance of taking the "clock" time necessary to communicate well and understand patient and family desires:

It's a matter of sort of expectations [...] matching sort of the team's expectations with the patient's expectations. If there's not that kind of communication, like, no one's having a good quality of life [...] I'm just thinking about resources and things. Yeah, I'm, like, always accessing our spiritual care service $[\ldots]$ they can take the time to gain more insight on sort of what's going on with the patient which is really helpful. And that's a relationship patients can use as well.

Many of the participants express how time slows down in ways that can improve quality of life, although some describe less positive experiences with stalled or lost time. Whether they experience slowed or stalled, or some other temporality, participants all describe shifting occupational priorities. 


\section{Shifts in occupational priorities and experiences}

Participants describe altered occupational priorities and temporal experiences related to their occupational engagement. A patient, for example, describes how occupational priorities shift nearing the EoL:

I don't need to make a living now. So that kind of changes your whole life. Like imagine at your age and you can go - being educated and getting all of this stuff to prepare for your future, imagine if all of a sudden there's nothing important for the rest of your life. You don't need money for anything. You don't need food, because there's people feeding you 24/7. There's nothing you could possibly want that you don't already have [...] everything that you thought was important isn't.

A spouse describes how priorities have become refocused, with all occupational energy being directed toward the person who is dying: “I don't have a life, a - whatever normal life is. Everything focuses kind of around him and what he needs."

Increased priority for belonging occupations. For many participants, engaging in belonging occupations, which support relationships, became higher priority, taking precedence over time spent with other occupations. A friend describes encouraging one patient to use his remaining life time for reconciliation:

I found out about [name], his oldest sister, and then his two brothers and, you know, the woman that he had married and stepdaughter and all this. So, I said - I encouraged yet again that he talk - because he was dying, to talk to his sister who he spoke highly of [...] so she came up twice for two weeks. Came up for two weeks. He hadn't seen her in 25 years. They had a magical time for two weeks. She left and then she came back and all she did was go up 
every day, hold his hand and talk for hours. Pushed the wheelchair. They had a great time and I think that - then she got her brothers to call him. I think that gave him a tremendous amount of support and reconciliation and peace. So, the sister was great. So, family's important [...] I think dying clarifies one's sense of time is limited if you got to say something, right?

Another interviewee in the same case describes witnessing the patient's reconciliation with his sister:

There was a second stage in the hospice when he was well. The third stage was 'silent times' when there were less words. His sister had come. We have a great relationship now. She is lovely. She came twice from [his home town, far away], ending 25 years of estrangement. It was wonderful to see them reunite. And to be someone who witnessed that. We need witnesses in life, I think, like witnessing weddings. I acted as, sort of, a witness to that. I would be sitting in the room. Those two would look at me and share their discoveries. I think it was lovely for a third party there. They looked at pictures of siblings. They hadn't talked or met each other for 25 years. It was great to support that woman as well. She was probably surprised, she would agree, by her emotions. How quickly she reconnected with Jeff. She was not a crier, but this one time she just cried and cried outside the door. It became almost more important towards the end to be there for [name], because [name] was being unresponsive. They held hands almost all day.

Other participants describe similar ways in which the embodiment of their relationships shifted near the EoL through touch and more belonging-focussed occupations. A patient's friend said: "I was not a hand holder. But that was more in third stage, silent stage, I changed, and I 
touched his hands and stroke his arms. We were not using words anymore. And that touching was important to him."

A patient talking about his relationship with his wife, describes how hospice provides the occupational space to engage together, "we still care very much for each other [...] we spend more time together. It probably helps deepen things." In another case, the sister of a patient talks about how the environment in hospice gives her the opportunity to engage in meaningful relationshipbuilding with her brother. Previously, doing occupations (e.g. visiting attractions, or hosting large gatherings) were prioritized, but following temporal rupture and reorganization, the two of them find space to get to know one another in a new way by engaging in belonging occupations:

We always have him over when he's in town and we do things, but it's always with kids and extended family or often lots of things going on. So, we never discussed anything, really. And I never really knew him. So, it was quite late in life when we had that.

A patient's son describes how he and other family members have prioritized spending time just being present with his father:

His siblings, which is nice, they come quite often. They don't have to do as much. They're not there as often as me 'cause I'm there twice a day and they're once every two or three days. But it's nice that they visit. They also, I think they're [...] Making up for lost time.

He also describes a desire to maintain the status quo in his relationship with his father by not changing the types of occupations in which they engage:

Sometimes I'll shop for him. But for the most part I don't do anything but visit. I really [...] maintaining the same relationship, I just want everything to be the same except he's dying and I'm visiting more often. I don't want to - I don't want to clean him up. I don't want to do any of that. And it's not just because I'm, like, I really don't want to. I just - I don't want 
him to have to have - to die knowing that by the end of his life his son had to clean his butt or something. That would make him sad. He wouldn't like that. It would make me sad. It would make him sad. It would be really sad. I don't want to do that. So I don't - I try not to do any caretaking except I do an awful lot more I.T. support [for my dad] than I used to because he's stuck in this situation. That's about it.

A patient describes how having a lack of access to meaningful occupation at some times of the day gives him a sense of time passing slowly, referring to his shifted experience of time within hospice:

I wouldn't associate it - I thought it was less to do with hospice as you're ill and you cannot - what can you do, how do you pass your day. So that you could go stir crazy, right, that is not a good thing [...] if you're in that stir-crazy state, then time will pass very slowly. You may be watching the clock all day long, trying to see how to pass the day because there's nothing to do.

For this participant, occupational priorities shifted - he needed meaningful occupation to create a more positive experience of time, but was at times unable to attain this.

Occupations that were once habitual and led to experiences of temporal compression may become more significant with the nearness of death. One patient discusses getting out of bed:

Every day I put my feet on the floor and if I can feel the floor, I go, thank you. What else can I say? I have no idea where this is going or how long it's going to last, so I just say thank you every day.

A different patient discusses altered temporal experience related to his ability to engage in occupation. He describes this experience as being both negative and positive: 
[Time's] much more debilitating for a start. You don't have the freedom to move around the way you normally do. So, it's kind of restrictive. I'm not mobile. I've got problems getting around. So that slows you down quite a bit $[\ldots]$ The days are longer $[\ldots]$ you're not able to move around and do exactly what you would like to do at any given time [...] it's just physical - an ability to move [...] [but] you have time to reflect on things.

The son of a patient describes how this time in which he gets to engage in the occupation of caring for his mother helps to ease him into the last phases of his mother's life:

Now is the last and kind of like the best chance for me to show love to my mom, at this kind of like this stage. And with this kind of long period of waiting period, I mean, we don't know when is the last day, last breath. So kind of like we are preparing [...] in a way we're kind of like gradually entering that process. And when the real death moment comes, I mean, we won't be that shocked or really disappointed. Because expected. We are prepared and expected, yeah. So in a way it's good because this take away our worries.

A patient's wife describes the impact of an unexpected shortened time together and the loss of occupations in which they had hoped to engage:

His mother died in '93. And see my mom died at 97. My dad 96. So we thought we were going to be together for a long time $[\ldots]$ we actually planned to go to Italy this year, you know, so every time we talk about Italy he gets upset because he wanted to go back again. Yeah. See some more things that he hasn't seen. Yeah, it's tough.

While re-organizing occupational priorities can support quality of life (e.g. engaging in belonging occupations), it can also cause a sense of loss, as it did in this case. 
Reflection as a meaningful occupation. Meaningful occupation repurposes at the EoL. Reflection appeared to emerge as a meaningful occupation in which people are able to engage when they are in hospice. One patient says that in hospice "you get more time to reflect on your life and the things you've done and what you didn't do. Although I've done most things that I wanted to do." He and his spouse talk about occupations in which they engaged in the past and find meaning in reflection upon their good life together. She feels that in hospice her relationship with him became "definitely more relaxed. 'Cause I did feel responsible for him [before hospice] [...] it's not my worry anymore. I can sit and enjoy the time with him.” But even so, she still feels that "everything is for [name of patient] [...] everything's for his comfort or what he would need." Hospice has opened the occupational space in the patient's life to engage in reflection: "I think about it [a particularly happy time in life] often [...] I got more time on my hands.” Through the occupation of reflection, he is still active: "I've been as far north as [city] and all through the Interior. I've painted a lot of hospitals and schools. I reflect on that sometimes [...] happy times they were $[\ldots]$ Lots of interesting people."

Some participants do not engage in reflective occupation. Rather, they engage in doing occupations surrounding the patient. For example, the son of one patient describes his mother's activities:

Quasi-staff, so some of the stuff that the staff does she'll do or she'll liaise with the staff [...] she'll make him salmon and cheese sandwiches 'cause he likes salmon and cheese sandwiches. That's fair. Or she'll go and check on what the food is and does he want any of the food. And even though they'll bring the food she'll sometimes bring some, you know, she'll do stuff. 
For another patient, time in hospice is filled with meaningful occupation, and therefore he feels a sense of temporal compression: "I find [time in hospice] goes by so quickly. Yeah, chitchat here, chitchat there and [...] day's gone." A patient's spouse talks about how having visitors and spending time with them reflecting and reminiscing impacts her temporality:

Oh, it makes the time go fast 'cause people come in, you're chatting, you know, sometimes when, you know, he was more alert, you know, we'd be talking about funny things that happened [...] very good, yeah. 'Cause you sit and you're chatting about different things and before you know it a few hours have passed, yeah [...] it [time in hospice compared with before] goes very fast. I can’t believe it, like, you know, it's Saturday and before you know it's Saturday again. And I just - no, time's just flown by.

Participant narratives demonstrate shifting occupational priorities and experiences following temporal ruptures, which appear to result in reorganization of time. These insights illuminate how temporality, occupation, and relationships interact and influence quality of life.

\section{Discussion}

This study has relevance with the Occupational Perspective on Health's (OPH) four occupational elements: doing, being, becoming, and belonging (Hitch et al., 2014; Rebeiro, 2001; Townsend \& Wilcock, 2004; Wilcock, 1998, 2006). These concepts highlight interaction with temporal and relational experience as they appear at EoL. The time for becoming may be drawing to a close, time for being may be enhanced for some, and time for belonging often becomes increasingly important. It became evident that participants experienced intersections between temporality, relationship, and these four aspects of occupation.

How dying patients distance from clock time has been documented previously (Adam, 2013; Ellingsen et al., 2013; Giuliani et al., 2015). This study expands upon the literature by describing 
how a reordering of the seemingly natural rhythms of life dictated by clock time has occupational and relational consequences. For example, some family members still have clock-dictated responsibilities such as work and school. This appears, for some, to lead to disconnect between the temporal experiences of the patient and significant others. Since belonging occupations can be described as those which "tie the person to others through relationships," disconnected temporality may disrupt the sense of belonging to one another (Essential Yeh \& McColl, 2019, p. 112;

Giuliani et al., 2015). Significant others who are predominantly situated in clock-based time may still focus on doing occupations, while others have adjusted their focus to being, belonging, and becoming occupations. Clock-focused individuals may neglect to temper time for doing (e.g. scheduling visitors for patients) with time for other aspects of occupation (e.g. simply being together). As an example, a patient and family member adjusted their focus away from doing occupations. They described how they previously engaged in doing-focussed occupations, such as visiting tourist attractions and hosting large gatherings, but after the patient moved to hospice, they gravitated toward belonging and being focussed occupations, such as reflecting on family ties, or simply being together outdoors. Similarly, in their study exploring families' interactions with professional carers at EoL, James, Andershed, and Ternestedt (2009) found that some positively described the time spent waiting for death because they had opportunity to "[talk] and [share] memories in a relaxed way" (p. 255). Pickens, O'Reilly, and Sharp (2010) found that families experience a sense of "temporal uncertainty of waiting for death," fostering a sense of becoming a new person as they prepare for death of the patient (p. 239).

Wilcock's taxonomy of occupation (the $\mathrm{OPH}$ ) describes being in close relation to temporality and relationship:

'Being' is about being true to ourselves, to our nature, to our essence and to what is distinctive about us to bring to others as part of our relationships and to what we do. To 'be' 
in this sense requires that people have time to discover themselves, to think, to reflect and to simply exist. (Wilcock, 2002, p. 5)

While the disorder of occupational and relational patterns that occurs as a result of temporal rupture was disruptive for participants - described as a state of uncertainty - it also highlighted the importance of the being side of occupation. During the time of dying, intense existential experiences of being may hold more meaning and be even more significant than the physical progress of illness (Pollard, 2006, p. 150).

Corroborating previous evidence and fitting with Park-Lala and Kinsella’s (2011) occupational orientation reworking everyday life, giving priority to relationships, and existential orientations, patients' occupational priorities shifted at the EoL to more existential and relational aspects of quality of life (Foley, 2004; Opacich, 2004; Pollard, 2006). For some, the hospice environment specifically enabled more time for being and reflective occupations because they no longer worried about the basic activities of daily living (Pickens et al., 2010).

Reflective occupations also relate to becoming in that people have time to take-stock of who and what they became through a framing of what they did and did not do, and the relationships in which they engaged. Fidler's (1983) three aspects of becoming are relevant here: 1) becoming I; 2) becoming competent; and 3) becoming a social being. An example is seen in one patient's story of reflecting upon the good life they and their family member had and who the patient became as a result. As another example, for one patient relational and temporal experiences influence their quality of life through occupations focused on becoming a social being as they more closely related to their family. Notably, experiences of time for becoming contributed to a greater sense of quality of life in hospice for both patients and significant others. Interestingly, when one patient discussed their temporal rupture experience in relation to doing (e.g. independent self-care), they described a negative experience of stalled temporality. Descriptions of engagement in doing 
occupations were often associated with poorer quality of life, while descriptions of becoming and belonging occupations were associated with better quality of life. This indicates a close connection between occupational factors, temporality, relationships, and quality of life.

\section{Implications for Practice \& Education}

The insights generated from participant narratives and theoretically-sensitized analysis have several potential implications for practice and education. It appears that re-orienting attention to becoming and belonging-focused occupations, such as reconciling with significant others, might be beneficial to quality of life at EoL. In light of this, hospice staff and volunteers may consider finding ways to foster the possibilities for engagement and reconciliation. For example, they can take time to learn more about what relationships and occupations have been significant for the patient throughout their life. Staff can also consider what barriers might exist for patients who want to engage in reconciliation and make efforts to remediate these barriers. These are also considerations for funding agencies who might be interested in enhancing quality of life at the EoL. For example, Jeff's sister's inability to afford the travel expenses associated with visiting him may have prevented their reconciliation and the additional familial reconciliations that occurred as a result. There could be a discretionary fund that assists in uniting significant others with patients. Funders can also consider the benefit of increased staffing, both to allow current team members more time for engaging with patients and to expand the diversity of professionals working in the setting.

Meaning is not created in a vacuum, but is negotiated within relational, temporal, and occupational experiences. Itis thus important that carers - significant others and professionals caring for individuals at the EoL - are attentive to and perhaps involved in the meaning-making of patients at EoL. It is critical to focus on individuals' reoriented priorities, including occupations 
focused on being, becoming, and belonging. Carers could address what individuals find to be most meaningful, including existential concerns that may be identified when engaging in reflective occupations (Lala \& Kinsella, 2011). For example, realizing that pharmaceutical pain management is only one part of quality of life, hospice staff may consider how they can enable individuals' engagement in occupations they find meaningful to facilitate quality of life. Given the time constraints already facing hospice staff, occupational therapists may be valuable additions to the team given their expertise in enabling meaningful and contextually attune engagement (Essential Yeh \& McColl, 2019; Russell \& Bahle-Lampe, 2016).

\section{Limitations \& Suggestions for Future Research}

Limitations within this study must be acknowledged. We recruited participants from a single hospice setting, limiting the diversity within our participant group. This also limited the experiences people had to one hospice. However, participants did describe experiences at a variety of hospitals and other healthcare access-points, and with a variety of healthcare professionals. We only recruited patients who were able to sustain a conversation, and therefore lack the perspectives of those who were unable to do so and the insights from their significant others. Finally, those who chose to participate may be naturally more relational, and therefore more likely to volunteer for this kind of study.

Future research could be undertaken to further explore ways to develop curriculum that attunes healthcare providers to the significance of relationships, temporality, and occupation for patients and their significant others in hospice settings. Moreover, research that expands upon the connections between specific kinds of occupation and how these interact with temporality in such a way that quality of life is enhanced and hindered would benefit healthcare professionals working in this field. 


\section{Conclusion}

These authors provide insights into complex interactions between temporal, occupational, and relational aspects of dying in hospice so scholars, practitioners, and educators can contribute to enriching and meaningful EoL experiences. As demonstrated in this study, patients and their significant others engage in complex meaning making processes. These insights can be used to educate both new and experienced healthcare providers regarding how they interact with individuals in a hospice setting.

\section{Acknowledgements, Funding, Declarations}

The authors gratefully acknowledge the St. Paul's Hospital Foundation for financially supporting this study and the Centre for Health Education Scholarship, Faculty of Medicine, UBC for human and material resource support. Particularly, the authors would like to acknowledge the contributions of Dr. Joanna Bates who brought critical insights to the study in its early stages. The authors have no conflicts of interest to declare. 


\section{References}

Adam, B. (2013). Timewatch: The social analysis of time. John Wiley \& Sons. https://books.google.ca/books?hl=en\&lr=\&id=D8j6Jq1SwM8C\&oi=fnd\&pg=PA1925\&dq=T imewatch:+The+Social+Analysis+of+Time.+\&ots=Jz6DpFvt9o\&sig=DPNrS086z4EZ4bEV7 wYueZNa_Fs\#v=onepage \&q=Timewatch\%3A The Social Analysis of Time.\&f=false

Andershed, B. (2006). Relatives in end-of-life care - Part 1: A systematic review of the literature the five last years, January 1999-February 2004. Journal of Clinical Nursing, 15(9), 11581169. https://doi.org/10.1111/j.1365-2702.2006.01473.x

Bale, C., Douglas, A., Jegatheesan, D., Pham, L., Huynh, S., Mulay, A., \& Ranganathan, D. (2016). Psychosocial Factors in End-Stage Kidney Disease Patients at a Tertiary Hospital in Australia. International Journal of Nephrology. https://doi.org/10.1155/2016/2051586

Chiu, Y.-W., Huang, C.-T., Yin, S.-M., Huang, Y.-C., Chien, C.-H., \& Chuang, H.-Y. (2010). Determinants of complicated grief in caregivers who cared for terminal cancer patients. Support Care Cancer, 18, 1321-1327. https://doi.org/10.1007/s00520-009-0756-6

Chochinov, H. M. (2011). Death, time and the theory of relativity. Journal of Pain and Symptom Management, 42(3), 460-463. https://doi.org/10.1016/j.jpainsymman.2010.12.001

Dumont, I., Dumont, S., \& Mongeau, S. (2008). End-of-Life Care and the Grieving Process: Family Caregivers Who Have Experienced the Loss of a Terminal-Phase Cancer Patient. Qualitative Health Research, 18(8), 1049-1061. https://doi.org/10.1177/1049732308320110

Ellingsen, S., Roxberg, Å., Kristoffersen, K., Rosland, J. H., \& Alvsvåg, H. (2013). Entering a World with No Future: A phenomenological study describing the embodied experience of time when living with severe incurable disease. Scandinavian Journal of Caring Sciences, 27(1), 165-174. https://doi.org/10.1111/j.1471-6712.2012.01019.x

Essential Yeh, H.-H., \& McColl, M. A. (2019). A model for occupation-based palliative care. 
Occupational Therapy In Health Care, 33(1), 1-16.

https://doi.org/10.1080/07380577.2018.1544428

Fidler, G. (1983). Doing and becoming: The occupational therapy experience. In G. Kielhofner (Ed.), Health Through Occupation: Theory and Practice in Occupational Therapy. F. A. Davis Co.

Foley, G. (2004). Quality of life for people with motor neurone disease: A consideration for occupational therapists. British Journal of Occupational Therapy2, 67(12), 551-553.

Giuliani, L., Piredda, M., Ghilardi, G., \& Marinis, M. G. D. (2015). Patients' Perception of Time in Palliative Care: A Metasynthesis of Qualitative Studies. Journal of Hospice \& Palliative Nursing, 17(5), 413-426. https://doi.org/10.1097/NJH.0000000000000179

Gumperz, J. J. (1992). Contextualization and understanding. In A. Duranti (Ed.), Rethinking context: Language as an interactive phenomenon (pp. 229-252). Cambridge University Press.

Hammell, K. R. W. (2014). Belonging, occupation, and human well-being: An exploration. Canadian Journal of Occupational Therapy, 81(1), 39-50. https://doi.org/10.1177/0008417413520489

Hardy, B., King, N., \& Firth, J. (2012). Applying the Pictor technique to research interviews with people affected by advanced disease. Nurse Researcher, 20(1), 6-10.

Hayes, J. E., Hart, B., \& Phillips, J. (2017). Specialist palliative care nurses' management of the needs of patients with depression. International Journal of Palliative Nursing, 23(6), 298305. https://doi.org/10.12968/ijpn.2017.23.6.298

Hitch, D., Pépin, G., \& Stagnitti, K. (2014). In the Footsteps of Wilcock, Part One: The Evolution of Doing, Being, Becoming, and Belonging. Occupational Therapy in Health Care, 28(3), 231-246. https://doi.org/10.3109/07380577.2014.898114 
Huot, S., Bulk, L. Y., Damiano, N., Delaisse, A.-C., Kardeh, B., Ogura, S., \& Forwell, S. (2019). Occupation \& Society [class presentation]. University of British Columbia.

James, I., Andershed, B., \& Ternestedt, B. M. (2009). The encounter between informal and professional care at the end of life. Qualitative Health Research, 19(2), 258-271. http://ovidsp.ovid.com/ovidweb.cgi?T=JS\&PAGE=reference $\& D=e m e d 9 \& N E W S=N \& A N=2$ 009040718

Irwin, S. A., Rao, S., Bower, K., Palica, J., Rao, S. S., Maglione, J. E., Soskins, M., Betterton, A. E., \& Ferris, F. D. (2008). Psychiatric issues in palliative care: recognition of depression in patients enrolled in hospice care. Journal of Palliative Medicine, 11, 158-163.

https://doi.org/10.1089/jpm.2007.0140

James, I., Andershed, B., \& Ternestedt, B. M. (2009). The encounter between informal and professional care at the end of life. Qualitative Health Research, 19(2), 258-271. https://doi.org/10.1177/1049732308329309

Jenkins, L., \& Codling, J. (2013). Results of the 2012/2013 Hospice Patient Survey General Report.

King, N., Bravington, A., Brooks, J., Hardy, B., Melvin, J., \& Wilde, D. (2013). The pictor technique a method for exploring the experience of collaborative working. Qualitative Health Research, 23(8), 1138-1152.

Kozlov, E., Phongtankuel, V., Prigerson, H., Adelman, R., Shalev, A., Czaja, S., Dignam, R., Baughn, R., \& Reid, M. C. (2019). Prevalence, Severity, and Correlates of Symptoms of Anxiety and Depression at the very End of Life. Journal of Pain and Symptom Management, 58(1), 80-85. https://doi.org/10.1016/j.jpainsymman.2019.04.012

Kuhl, D., Stanbrook, M. B., \& Hébert, P. C. (2010). What people want at the end of life. Cmaj, 182(16), 1707. https://doi.org/10.1503/cmaj.101201 
Lala, A. P., \& Kinsella, E. A. (2011). A phenomenological inquiry into the embodied nature of occupation at end of life. Canadian Journal of Occupational Therapy, 78(4), 246-254. https://doi.org/10.2182/cjot.2011.78.4.6

Larson, E. A. (2004). The time of our lives:The experience of temporality in occupation. Canadian Journal of Occupational Therapy, 71(1), 24-35.

Larson, E. A., \& Zemke, R. (2003). Shaping the temporal patterns of our lives: The social coordination of occupation. Journal of Occupational Science, 10(2), 80-89. https://doi.org/10.1080/14427591.2003.9686514

Lövgren, M., Hamberg, K., \& Tishelman, C. (2010). Clock Time and Embodied Time Experienced by Patients With Inoperable Lung Cancer. Cancer Nursing, 33(1), 55-63. https://doi.org/10.1097/NCC.0b013e3181b382ae

Mills, K., \& Payne, A. (2015). Enabling occupation at the end of life: A literature review. Palliative and Supportive Care, 13(06), 1755-1769. https://doi.org/10.1017/S1478951515000772

Morrison, R., Gómez, S., Henny, E., Tapia, M. J., \& Rueda, L. (2017). Principal approaches to understanding occupation and occupational science found in the Chilean journal of occupational therapy (2001-2012). Occupational Therapy International, 2017, 1-11. https://doi.org/10.1155/2017/5413628

Nimmon, L. (2014). Meaning making within the social activity domain of health maintenance: The role of social networks. University of British Columbia.

Nimmon, L., Bates, J., Kimel, G., \& Lingard, L. (2018). Patients with heart failure and their partners with chronic illness: interdependence in multiple dimensions of time. Journal of Multidisciplinary Healthcare, 11, 175-186. https://doi.org/10.2147/JMDH.S146938

Opacich, K. J. (2004). Reconstructing occupation after HIV infection: Lessons from women's 
experiences. International Journal of Therapy and Rehabilitation, 11(11), 516-524.

Pickens, N. D., O'Reilly, K. R., \& Sharp, K. C. (2010). Holding on to Normalcy and Overshadowed Needs: Family Caregiving at End of Life. Canadian Journal of Occupational Therapy, 77(4), 234-240. https://doi.org/10.2182/cjot.2010.77.4.5

Pollard, N. (2006). JOS comment: Is dying an occupation? Journal of Occupational Science, 13(2-3), 149-152. https://doi.org/10.1080/14427591.2006.9726508

Rebeiro, K. L. (2001). Enabling Occupation: The Importance of an Affirming Environment. Canadian Journal of Occupational Therapy, 68(2), 80-89. https://doi.org/10.1177/000841740106800204

Robertson, M. (2014). Experiences of time: A qualitative inquiry into experiences of time as described by palliative care inpatients. Palliative and Supportive Care, 13(1), 67-73. https://doi.org/10.1017/S1478951513000886

Rokach, A. (2016). The Dying and Those Who Care for Them. Journal of Patient Care, 2015.

Russell, M., \& Bahle-Lampe, A. (2016). The Care for the Dying: A critical historical analysis of occupational therapy in hospice. The Open Journal of Occupational Therapy, 4(2). https://doi.org/10.15453/2168-6408.1216

Sawyer, J. M., Sallnow, L., Kupeli, N., Stone, P., \& Sampson, E. L. (2019). Social networks, social capital and end-of-life care for people with dementia: A realist review. BMJ Open, 9(12), 1-17. https://doi.org/10.1136/bmjopen-2019-030703

Schellinger, S. E., Anderson, E. W., Frazer, M. S., \& Cain, C. L. (2018). Patient Self-Defined Goals: Essentials of Person-Centered Care for Serious Illness. American Journal of Hospice and Palliative Medicine, 35(1), 159-165. https://doi.org/10.1177/1049909117699600

Sercu, M., Beyens, I., Cosyns, M., Mertens, F., Deveugele, M., \& Pype, P. (2018). Rethinking End-of-Life Care and Palliative Care: Learning From the Illness Trajectories and Lived 
Experiences of Terminally Ill Patients and Their Family Carers. Qualitative Health Research, 28(14), 2220-2238. https://doi.org/10.1177/1049732318796477

Tang, W.-R., Aaronson, L. S., \& Forbes, S. A. (2004). Quality of life in hospice patients with terminal illness. Western Journal of Nursing Research, 26(1), 113-128.

Townsend, E., \& Polatajko, H. J. (2007). Advancing an occupational therapy vision for health, well-being, and justice through occupation. Ottawa, ON: CAOT Publications ACE.«Enabling Occupation II Présente Une Vue En Coupe Tranversale Du MCRO-P Pour Définir et Délimiter Le Domaine de Préoccupation Des Ergothérapeutes, c'est-Àdire l'occupation Humaine.

http://citeseerx.ist.psu.edu/viewdoc/download?doi=10.1.1.453.4351\&rep=rep1\&type=pdf

Townsend, E., \& Wilcock, A. (2004). Occupational justice and client centered practice: A dialogue in progress. Canadian Journal of Occupational Therapy, 71(2), 75-87.

Untas, A., Thumma, J., Rascle, N., Rayner, H., Mapes, D., Lopes, A. A., Fukuhara, S., Akizawa, T., Morgenstern, H., Robinson, B. M., \& Pisoni, R. L. (2011). The associations of social support and other psychosocial factors with mortality and quality of life in the dialysis outcomes and practice patterns study. Clinical Journal of the American Society of Nephrology, 6(1), 142-152. https://doi.org/10.2215/CJN.02340310

Waterworth, S., Gott, M., Raphael, D., \& Barnes, S. (2011). Older people with heart failure and general practitioners - temporal reference frameworks and implications for practice. Health and Social Care in the Community, 19(4), 412-419. https://doi.org/10.1111/j.13652524.2010.00984.x

Wilcock, A. (1998). Occupation for Health. British Journal of Occupational Therapy, 61(8), 340345. https://doi.org/10.1177/030802269806100801

Wilcock, A. (2002). Reflections on doing, being and becoming. Australian Occupational Therapy 
Journal, 46(1), 1-11. https://doi.org/10.1046/j.1440-1630.1999.00174.x

Wilcock, A. (2006). An occupational perspective on health (2nd ed.). Slack.

World Health Organization. (2018). Palliative Care. https://www.who.int/en/news-room/factsheets/detail/palliative-care 